\title{
Constraint-Referenced Analytics of Algebra Learning
}

\author{
Scot M. Sutherland \\ University of California, Davis \\ ssutherland@ucdavis.edu \\ Tobin F. White \\ University of California, Davis
}

\begin{abstract}
The development of the constraint-referenced analytics tool for monitoring algebra learning activities presented here came from the desire, firstly, to take a more quantitative look at student responses in collaborative algebra activities, and secondly, to situate those activities in a more traditional introductory algebra setting focusing on procedural understanding. Procedural skill was analyzed by modelling the complexity of attempts to make equivalent transformations of algebraic expressions. The constraint-referenced analytics system uses log files of student inputs on a classroom network of handheld devices to measure success rate as students attempt to replace one algebraic expression with another equivalent expression. The analytics engine produced psychometrically verifiable results. Moving averages of student performance revealed that when students experienced a period of struggle and persisted in attempting similar transformations, an apparent conceptual shift led to subsequent success. Students also responded to periods of struggle by switching to familiar tasks or choosing non-participation.
\end{abstract}

Keywords: Learning analytics, measurement, psychometrics, assessment, algebra learning, procedural knowledge, conceptual knowledge, collaborative networks, classroom networks.

\section{INTRODUCTION}

The recent emergence of tools and techniques for educational data mining and learning analytics have introduced an array of new resources for automatically monitoring, assessing, and supporting student performance within computer-based learning environments (Baker \& Inventado, 2014). Automated approaches have been used to capture a wide variety of skills and behaviours, including science inquiry skills in online microworlds (Gobert, Sao Pedro, Raziuddin, \& Baker, 2013), player learning within video game play (Halverson \& Owen, 2014), help-seeking behaviours in online problem-solving environments (Roll, Baker, Aleven, \& Koedinger, 2014), and programming fluency in computer science education contexts (Blikstein et al., 2014). To date, many of these efforts have focused on online environments, but the potential for analytics tools and approaches to support face-to-face instruction in classroom settings may be equally rich.

This article investigates one such approach, implemented in the context of classroom network tools developed for an introductory high school Algebra course. We present an initial exploration of constraint-referenced analytics, an automated way to measure the complexity of processes involved in making equivalent algebraic transformations by referencing digitally encoded constraint-based models. 
(2016). Constraint-referenced analytics of algebra learning. Journal of Learning Analytics, 3(3), 143-169.

http://dx.doi.org/10.18608/jla.2016.33.8

The design of the analytics engine combines constraint-based models of algebra found in intelligent tutors (Mitrović, Mayo, Suraweera, \& Martin, 2001) with models of complexity informed by algebralearning literature to develop an automated form of measurement capable of detecting periods of struggle and student responses to that struggle. Measurements were taken by parsing log file records of student inputs on a classroom network of handheld devices while they worked in pairs to construct or transform algebraic expressions and equations. The approach produced psychometrically verifiable results without embedding preconceived assessment items or performance measurements in the design of the learning activities.

Constraint-based models for intelligent tutors emerged from the need to encode contextual properties rather than rules-based procedures for ill-defined and unstructured domains of knowledge (Mitrović, 2012). Whereas rules-based models predefine a set of outcome goals and correct students when they stray from a productive path, constraint-based models define what constitutes valid activity within the domain, simply explaining the reasons for a violation of the constraints. For example, a student given the equation $2(x+6)=3 x(x+6)$ may distribute the terms producing $2 x+12=3 x^{2}+18 x$. A rules-based system focused on solving for $x$ would prompt the user to try again. A constraint-based system would allow the transformation without comment since the procedure did not violate any algebraic domain constraints. If the student mistakenly attempted to distribute the right side of the equation as $3 x^{2}+6$, the constraint-based system would explain that both resulting terms must contain at least an $x$ term since the distributed term contains an $\mathrm{x}$. A constraint-based system does not trace progress through a predefined set of solution paths, but captures violations of constraints that define a particular context without reference to a specific goal. Students in traditional algebra classes often encounter tasks that involve replacing one expression with an equivalent expression (Choppin, Clancy, \& Koch, 2012). The relative complexities of the algebraic context and the transformation attempt, and patterns of repeated attempts, may reveal periods of struggle and distinct ways that students respond to that struggle. Below, we present an exploratory investigation of the ways a constraint-based approach to analyzing these transformations might be used to monitor student learning in Algebra.

\section{THEORETICAL FRAMEWORK}

In this section, we frame the present study with a definition of conceptual knowledge from a brief review of definitions found in mathematics literature, followed by a review of sources of the difficulties that students face when learning algebra. The section concludes with a presentation of the rationale for constraint-referenced measurement and its intelligent tutor roots.

\subsection{Conceptual Knowledge in Mathematics}

Mathematical thinking is generally taken to comprise both procedural and conceptual knowledge (Hiebert, 2013). While researchers generally agree on both the definition and measurement of procedural knowledge as the ability to perform mathematical processes to reach a desired outcome, less agreement exists for conceptual knowledge. In an exhaustive review of mathematics education and educational psychology literature, Crooks and Alibali (2014) identified six definitions of conceptual 
(2016). Constraint-referenced analytics of algebra learning. Journal of Learning Analytics, 3(3), 143-169. http://dx.doi.org/10.18608/jla.2016.33.8

knowledge: 1) connection knowledge, 2) general principle knowledge, 3) knowledge of principles underlying procedures, 4) category knowledge, 5) symbol knowledge, and 6) domain structure knowledge. Researchers also made a distinction between explicit conceptual knowledge that could be expressed or verbalized and implicit knowledge that could be demonstrated but not explained. Conceptual understanding, defined as knowledge of principles underlying procedures, was primarily found in studies of understanding cardinality or inversion among preschool and elementary students. Less than one quarter of studies on equivalence contained any definition of conceptual knowledge, and those that did variously defined it as connection knowledge, general principle knowledge, category knowledge, or symbol knowledge.

\subsection{Sources of Difficulty for Algebra Learners}

Mathematics education researchers have documented several sources of difficulty that students face when making the transition from arithmetic to algebra. Here we summarize three of these sources of difficulty: mathematical task complexity, symbolic complexity and meaning, and structural-procedural duality, reserving more space for a review of cognitive complexity.

A significant portion of many traditional algebra courses involves reducing algebraic expressions to their simplest form. The number of procedural steps necessary and the kinds of processes required contribute to the mathematical complexity of the task. Researchers measure procedural skill by assessing the sophistication and appropriateness of procedural methods that learners use (Ball, Pierce, \& Stacey, 2003; Warren, 2003; Saldanha \& Kieran, 2005; Rossi, 2008). Learners sometimes invent their own sequential procedures in both algebra and arithmetic when they encounter unfamiliar contexts (Linchevski \& Livneh, 1999; McNeil \& Alibali, 2005; Ambrose, Baek, \& Carpenter, 2013).

Familiar mathematical symbols that have very few meanings in arithmetic take on multiple meanings depending upon the context in algebra. Studies found that algebra learners used surface features, visual cues, and symbolic meaning to make operational decisions (Kirshner, 1993). The symbolic context influenced the words learners used and the meaning they attached to the symbols (Wagner \& Parker, 1993). Linchevski and Livneh (1999) found that student misconceptions of the meaning of mathematical symbols were consistently applied in different algebraic situations, which led to incorrect answers in some contexts and correct answers in others. These misconceptions were traced to operational processes learned in arithmetic (Booth, 1988; Linchevski \& Livneh, 1999).

Mathematics by nature is both structural and operational, and many sources of difficulty identified by researchers involve this dual nature of mathematical concepts (Sfard, 1991; Sfard \& Linchevski, 1994). The notion of equivalence gives algebra much of its power, allowing any algebraic expression to be replaced by any equal expression (Gattegno, 1974; Kieran, 1981). A structural knowledge of equality as a relation has been associated with success in algebra (Denmark et al., 1976; Jones, Inglis, Gilmore, \& Dowens, 2012; Jones, Inglis, Gilmore, \& Evans, 2013). Structural and operational knowledge in algebra literature is analogous to conceptual and procedural knowledge previously reviewed in other mathematics education research. 
(2016). Constraint-referenced analytics of algebra learning. Journal of Learning Analytics, 3(3), 143-169.

http://dx.doi.org/10.18608/jla.2016.33.8

One particular study brought the connection between conceptual and procedural knowledge into focus. Filloy and Rojano (1989) found that 13- and 14-year-old students could use inverse arithmetic operations to solve equations such as $3 x+2=6$, but resorted to a guess and check approach based on arithmetic when confronted with $5 x+2=2 x+6$. In no instance did students spontaneously operate on the unknown in the absence of instruction. A structural conception of the unknown as an object is needed for operations to be performed with it or on it. Results were based upon a measure of procedural skill as a reflection of conceptual understanding of the principles underlying the procedures. Developing the ability to operate with and on the unknown has been established as an important aspect of pre-algebra learning (Linchevski, 1995).

\subsection{Cognitive Complexity}

Cognitive complexity can be characterized as the number of cognitive processes that must be coordinated to accomplish a particular task. Research that compared expert and novice performance led to the notion of chunking, knowledge constructed by chunking together disparate patterns and concepts into meaningful wholes called schema. Experts were able chunk together larger, more complex schemata than novices (Chase \& Simon, 1973; Chi, Feltovich, \& Glaser, 1981). These studies show that, with enough effortful practice, novices can develop expertise in many areas of cognitive skill.

Conceptual understanding of mathematics largely develops through recognizing patterns and relations between mathematical elements, and being able to classify them in different ways (Hiebert, 2013). Procedural knowledge cannot be reported, it must be performed (Rittle-Johnson, Siegler, \& Alibali, 2001), and researchers acknowledge that executing a series of procedural steps to achieve a particular answer can be done without much more than recognition of surface features. However, conceptual and procedural knowledge are now seen as inextricably intertwined. It is hard to imagine conceptual understanding without procedural skill. Rote procedural skill is more likely to occur when the student is taught the procedure than when they figure it out for themselves (Hiebert, 2013). Students are able to develop formal mathematical procedures better when they engage in sense making activities (Choppin et al., 2012) and when they are able to persist in problem solving (Renninger, Hidi, \& Krapp, 2014). Initial failure can be productive if the students persist long enough and learn from their failures until they reach a moment of insight that leads to a conceptual shift in understanding. A class of problems that were once a struggle become easier to solve (Kapur, 2011; 2016).

\subsection{Intelligent Tutors and Algebra Learning}

Cognitive tutors focused on procedural understanding of mathematics (Mitrović, Koedinger, \& Martin, 2003). Students learned how to get an answer or reach a predetermined goal-state, but struggled when making the transition to algebra. A structural understanding of mathematics that enabled students to see the relations between mathematical elements was found to be associated with success in algebra (Linchevski \& Herscovics, 1996; Henningsen \& Stein, 1997). Learners could then see the possible courses of action and choose those appropriate to the task or purpose (Kieran, 2004). Cognitive tutors addressed this problem by modelling all the known solution paths and prompting learners to choose one. III- 
(2016). Constraint-referenced analytics of algebra learning. Journal of Learning Analytics, 3(3), 143-169.

http://dx.doi.org/10.18608/jla.2016.33.8

defined or unstructured domains of knowledge that relied on meaningful patterns or activities without a clear goal could not be modelled with ACT-based tutors (Mitrović, 2012).

Constraint-based intelligent tutors addressed knowledge domains beyond the reach of cognitive tutors. By modelling domains of knowledge with constraints, intelligent tutors focused on task constraints in a particular context. Any actions that fell outside the constraints that define the situation were flagged with a message identifying the constraint as violated and an explanation of the reason. For example, if a learner attempted to combine $3 x+1$ as $4 x$, the system would respond with, "A linear term like $3 x$ cannot be combined with a constant term like 1." The ability to identify patterns and their meanings made it possible to develop constraint-based tutors for fields like design (Mitrović \& Weerasinghe, 2009) and collaborative learning environments (Baghaei, Mitrović, \& Irwin, 2007).

Despite advances in constraint-based modelling, intelligent algebra tutors, whether production rulesbased or constraint-based, largely function the same way in learning situations. A student goes through a series of tasks on a computer or digital device guided by the automated tutor. Assessment items are either embedded in the learning sequence or given separately. Until now, constraint-based modelling has not been used as a reference for measurement of learning activity.

\section{METHODS}

This section begins with a description of the two learning environments and activities used in the study, followed by a description of data collection and the study participants. We then present a detailed description of the log file and constraint-referencing parsers that construct the cognitive complexity model used to measure task difficulty and trace individual performance over time.

\subsection{Classroom Network Activity Designs}

The study reported in this paper was conducted in the context of a larger ongoing design-based research project focused on developing and studying collaborative learning activities for middle- and high-school mathematics using classroom networking tools (White, 2006; 2013). Broadly, project designs aim to map the relationships among pairs or small groups of students to different aspects of a mathematical problem or situation through personal digital devices connected on a network. Posing tasks that require coordination of those elements helps to structure collaboration within the groups. Examples along these lines include 1) pairs of students each moving a single Cartesian point in order to jointly form linear functions (White, Wallace, \& Lai, 2012), 2) groups of four students each manipulating different vertices in order to explore changing and invariant attributes of a shared quadrilateral (Lai \& White, 2012; 2014), or 3) multiple students respectively analyzing one among multiple linked function representations in order to investigate a problem (White \& Lai, 2008; White, 2009; White \& Pea, 2011).

All of these designs are intended to foster student participation in discussions and investigations of the mathematical relationships around which interactions between group members are organized. Consequently, prior research studies featuring these tools have primarily focused on the analysis of 
(2016). Constraint-referenced analytics of algebra learning. Journal of Learning Analytics, 3(3), $143-169$.

http://dx.doi.org/10.18608/jla.2016.33.8

discourse, interaction, and mathematical reasoning at the small group level. In contrast, the goal of the present study is to explore methodological tools and approaches that might complement group-level analyses of forms of interaction supported by these designs with automated and ongoing means of monitoring and examining the ways individual students reason and perform over time as they participate in these designed environments and collaborative learning activities. Moreover, and in contrast to other project designs situated in more open-ended and applied problem-solving contexts such as cryptography (White, 2009), the activities featured in the present study were specifically designed to be relevant in and responsive to classroom settings featuring more conventional curricular and instructional approaches and emphasizing procedural knowledge.

The data for the present study were collected during implementation of two classroom network designs for an introductory Algebra course - one, called Terms and Operations, centred on polynomial expressions, and the other, called Two-Sides, focused on solving algebraic equations. Both designs utilized Texas Instruments graphing calculators and a TI-Navigator ${ }^{\mathrm{TM}}$ classroom network in combination with the NetLogo modelling platform (Wilensky, 1999) and Hubnet architecture (Wilensky \& Stroup, 1999). To capture network activity data, the Terms and Operations activity environment (White, Sutherland, \& Lai, 2010) was modified to capture extensive log file data of student inputs. The Two-Sides activity environment (Sutherland \& White, 2011) was designed with log file capture in mind. Both activities are described in detail below.

\subsubsection{Terms and Operations}

Pairs of students construct a collective expression by adding, subtracting, multiplying, or dividing a series of monomial terms in the Terms and Operations activity environment. Each student uses the arrow keys on the calculator to control the position of an icon in a window on a shared display at the front of the classroom. The teacher populates the window with monomial terms that float around inside the same window.

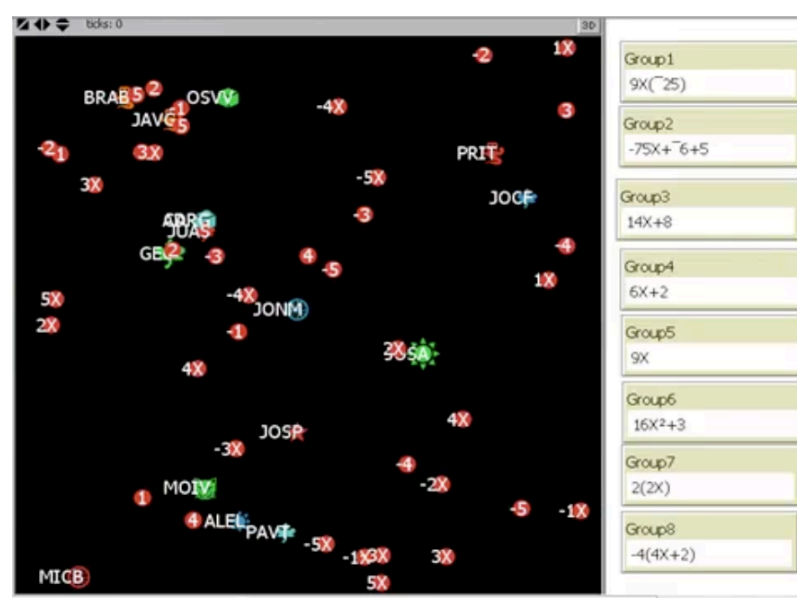

Figure 1: Terms and Operations Shared Display

Each student can capture a term by moving the icon over a floating term. When a term has been successfully captured, the calculator prompts the student to add, subtract, multiply, or divide the term to combine it with the expression they are constructing. The calculator then prompts the student or her 
(2016). Constraint-referenced analytics of algebra learning. Journal of Learning Analytics, 3(3), 143-169.

http://dx.doi.org/10.18608/jla.2016.33.8

partner to rewrite the resulting expression. Pairs of students either take turns capturing terms and rewriting expressions or one student captures a term and chooses an operation for the other student to rewrite. If the student successfully rewrites the expression with an equivalent form, the collective expression on the shared display is updated to reflect the changes the pair made. If the rewritten expression is not equivalent, the shared display does not update the changes and the expression remains as it was before the term was captured.

a)

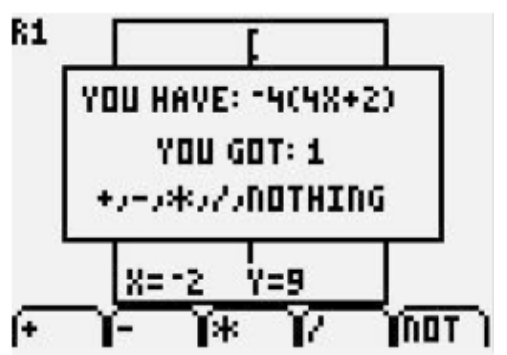

b)

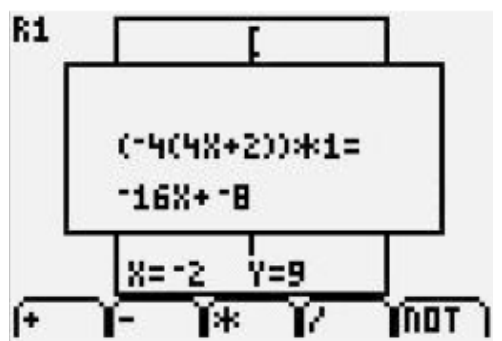

Figure 2: Terms and Operations Student Calculator Screens. Student calculator screens featuring a) captured term and operation choices and b) a collective expression under the chosen term and operation and an equivalent student entry.

The teachers conducted a variety of activities during data collection for this study. Four sessions focused on operating with integer terms. The teachers subsequently asked students to construct linear expressions, quadratic expressions, and expressions involving parentheses. Rewriting involved simplifying, factoring, distributing and combining like terms, and occasionally splitting terms. Students were often given the freedom to use any operation, but were sometimes required to use all four operations during expression construction or restrict themselves to various combinations of operations. Fifteen Terms and Operations sessions were included in this study.

\subsubsection{Two-Sides}

Each member of a student pair is assigned to either the left or right side of an algebraic equation in the Two-Sides activity environment. To create a new equation, each student in the pair must enter a valid algebraic expression. The networked relationship between the two students' calculators in the TwoSides environment acts as an equal sign for the equation they share. Each member can replace the expression on her own side of the equation by entering any equivalent expression. When partners want to transform the entire equation, they must coordinate the transaction by pressing the operate button and entering equivalent operations on both sides. The system updates the equation only if the operations and transformations by both students are equivalent. Only transformations of the expression on one side of the equation were included in this study to align with the transformations recorded in the Terms and Operations environment. 
(2016). Constraint-referenced analytics of algebra learning. Journal of Learning Analytics, 3(3), 143-169.

http://dx.doi.org/10.18608/jla.2016.33.8

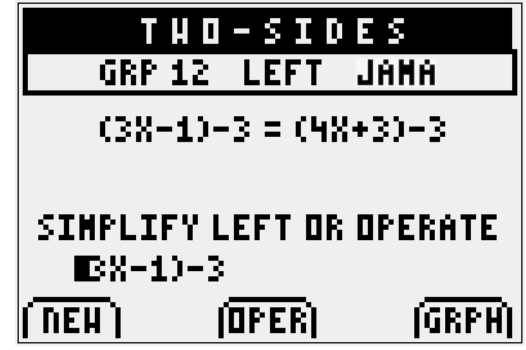

Figure 3: Left-Side Student Entering an Equivalent Expression in Two-Sides. A student simplifies the left side of the equation after the pair has subtracted a $\mathbf{3}$ from both sides. The calculator display will update only if the student successfully enters an expression equivalent to (3x-1)-3.

During Two-Sides sessions, students constructed linear and quadratic equations that were then solved by another pair. This study included two Two-Sides sessions.

These two activity environments were developed as part of a larger research focus on technologysupported collaboration, which provided a context for the activities developed for this study. The designers endeavored to map social relations to mathematical constructs; in the first case by supporting joint construction of algebraic expressions; in the second by assigning opposite sides of an algebraic equation to each member of a dyad. This study focuses on the inputs of individual students captured from network activity to validate the constraint-referenced metrics of cognitive complexity. Collaborative focus of the activity designs supports subsequent analysis of student responses to periods of struggle.

\subsection{Data Collection and Participants}

Data collected in the spring semester of 2012 during classroom network activities was conducted in two algebra lab support classes ( $\mathrm{N}=54$ students) taught by the same teacher in a racially diverse comprehensive urban high school, grades $9-12$, with $70 \%$ of the population of approximately 2000 students identified as living in low socioeconomic conditions. All students included in the study were selected based upon concurrent enrollment in Algebra Lab and Algebra I classes. The block schedule at the high school meant that classes covered a full year course in Algebra in approximately 4.5 months, reported as two separate semester-long classes. Students were identified for placement in the Algebra Lab when they had been unable to pass the Algebra I course.

During the sessions included in this study, 14,262 lines of log file data were collected from the classroom network environment. Each session was recorded with a wide-angle video of the classroom and a screen capture video of the shared display on the classroom network server. The data set includes 17 sessions (15 Terms and Operations; 2 Two-Sides) of algebra activities conducted on the classroom network. The parser identified 1794 transformations in which students attempted to replace an algebraic expression with an equivalent expression. 
(2016). Constraint-referenced analytics of algebra learning. Journal of Learning Analytics, 3(3), 143-169. http://dx.doi.org/10.18608/jla.2016.33.8

\subsection{Log File Parser}

The log file parser filters out sequences of log file entries that do not involve mathematical transformations and aggregates each transformation sequence into a single line in canonical form. Transformation sequences differ for each activity environment, so the parser applies a different grammar to each.

Table 1: Canonical Form of Transformation Sequences

\begin{tabular}{lcc}
\hline Description & Type & Example \\
\hline Time stamp & Time & $09: 35: 38$ \\
Group Number & Integer & 2 \\
Group Members & String & Florence Ali \\
Code & String & Equivalent, Not Equivalent, Syntax Error \\
Student taking action & String & Florence \\
Original Expression & String & $3 \mathrm{X}+5-\mathrm{X}$ \\
Replacement Expression & String & $2 \mathrm{X}+5$ \\
\hline
\end{tabular}

\subsection{Constraint-Referencing Parser}

The constraint-referencing parser forms the core of the analytics engine developed for this study and contains a constraint-based model of the portion of algebra relevant to this study. On the first pass through the data, the parser grammar references the model to identify six elements of each algebraic expression. Algorithms in the analytics engine enumerate the elements and add additional fields to each record for the number of constant terms, linear terms, quadratic terms, negative symbols, parenthesis pairs, and a binary indicator to identify whether the parenthesis have mathematical meaning.

Table 2: Expression Elements Identified by the Constraint-referencing Parser

\begin{tabular}{|c|c|}
\hline Element & Description \\
\hline Constant Symbols & $\begin{array}{c}\text { How many constant symbols does the expression have? } \\
\text { Example: } 2 x+3-1 \text { has } 2 \text { constant symbols. }\end{array}$ \\
\hline Linear Symbols & $\begin{array}{l}\text { How many linear symbols does the expression have? } \\
\text { Example: } 2 x-3+x \text { has } 2 \text { linear symbols. }\end{array}$ \\
\hline Quadratic Symbols & $\begin{array}{l}\text { How many quadratic symbols does the expression have? } \\
\text { Example: } 2 x^{2}+3 x \text { has } 1 \text { quadratic symbol. }\end{array}$ \\
\hline Negative Symbols & $\begin{array}{l}\text { How many negative symbols are contained in the expression? } \\
\text { Example: }-2(x-3) \text { has } 2 \text { negative symbols. }\end{array}$ \\
\hline Parentheses Pairs & $\begin{array}{l}\text { How many parenthesis pairs are present in the expression? } \\
\text { Example: } 2 x+(3-x) \text { has } 1 \text { parenthesis pair. }\end{array}$ \\
\hline Nested? & $\begin{array}{l}\text { Would simply eliminating the parentheses change the mathematical value? } \\
\text { Example: } 2+(3 x-3) \text { the parentheses are not mathematically meaningful } \\
\qquad 2(3 x-3) \text { the parentheses are mathematically meaningful }\end{array}$ \\
\hline
\end{tabular}

Constraint-based models are able to represent ill-defined and unstructured domains of knowledge because they can assign semantic meaning to patterns (Muresan, 2013; Mitrović, 2012). Referencing 
(2016). Constraint-referenced analytics of algebra learning. Journal of Learning Analytics, 3(3), 143-169.

http://dx.doi.org/10.18608/jla.2016.33.8

constraints in the model gives meaning to symbol patterns in the expression, just as students must recognize that a number next to an $\mathrm{x}$ is a linear term and must be kept separate from a constant term in certain contexts. Constraint referencing gives the analytics engine fine-grained access to the ways students struggle as they manipulate algebraic expressions.

\subsection{Model of Cognitive Complexity}

The analytics engine measures the cognitive complexity of transforming an algebraic expression by comparing the rate of success for replacing original expressions with a corresponding equivalent expression to a model of the cognitive complexity of the transformation. Each of the research streams discussed above suggests that the difficulty of making meaning in an algebraic context is related to the number of different algebraic elements that must be recognized and coordinated. To test this relationship, the constraint-referenced parser takes a second pass through the data to flag which of the six elements are present in the original expression and how they differ from the elements in the replacement expression. The complexity of the original expression defines the complexity of the algebraic context, whereas the differences in complexity between the original and replacement expressions define the complexity of the transformation attempt. The number of distinct kinds of elements the learner must coordinate is captured by the differences between the original and replacement expressions.

Table 3: Record Fields After Second Constraint-referencing Parser Pass

\begin{tabular}{|c|c|c|c|}
\hline \multicolumn{2}{|c|}{ Description } & Type & Example \\
\hline \multicolumn{2}{|c|}{ Time stamp } & Time & $09: 35: 38$ \\
\hline \multicolumn{2}{|c|}{ Group Number } & Integer & 2 \\
\hline \multicolumn{2}{|c|}{ Group Members } & String & Florence Ali \\
\hline \multicolumn{2}{|c|}{ Code } & String & Equivalent, Not Equivalent, Syntax Error \\
\hline \multicolumn{2}{|c|}{ Student taking action } & String & Florence \\
\hline \multicolumn{2}{|c|}{ Original Expression } & String & $3 x+5-x$ \\
\hline \multicolumn{2}{|c|}{ Replacement Expression } & String & $2 X+5$ \\
\hline \multirow{7}{*}{ 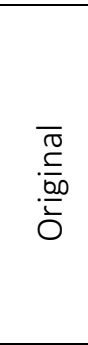 } & Constant Terms & Integer & 1 \\
\hline & Linear Terms & Integer & 2 \\
\hline & Quadratic Terms & Integer & 0 \\
\hline & Negative Symbols & Integer & 1 \\
\hline & Parenthesis Pairs & Integer & 0 \\
\hline & Nested? & Integer & 0 \\
\hline & Complexity & Integer & 3 (Constant, Linear, Negative are present) \\
\hline \multirow{7}{*}{ 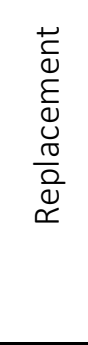 } & Constant Terms & Integer & 1 \\
\hline & Linear Terms & Integer & 1 \\
\hline & Quadratic Terms & Integer & 0 \\
\hline & Negative Symbols & Integer & 0 \\
\hline & Parenthesis Pairs & Integer & 0 \\
\hline & Nested? & Integer & 0 \\
\hline & Complexity & Integer & 2 (Constant and Linear are present) \\
\hline \multicolumn{2}{|c|}{ Transformation Complexity } & Integer & 1 (Difference between Original and Replacement) \\
\hline
\end{tabular}


(2016). Constraint-referenced analytics of algebra learning. Journal of Learning Analytics, 3(3), 143-169.

http://dx.doi.org/10.18608/jla.2016.33.8

Other models of complexity could be created that sum the total number of elements present, flag other operators (i.e., add, multiply, divide, square root, etc.), and take into the account the kinds of operations used during the transformation. Weights could be added to adjust the relative contributions each element makes to cognitive complexity. This simple model represents a first step toward testing the validity of constraint referencing as an approach to measuring cognitive difficulty and illustrating how the analytic results can shed light on learning activities.

\section{$4 \quad$ RESULTS}

In this section, we present psychometric validity of the cognitive model as an instrument for measuring task complexity and the resulting traces of individual student performance over time that reveal periods of struggle.

\subsection{Complexity Model Validation}

The constraint-referencing parser found 1795 attempts in both classes to make an equivalent transformation of an algebraic expression, 1394 successful and 401 unsuccessful. Table 6 shows the breakdown of attempts for both classes, and each class separately. Measurement against a constraint produces binary results - a transformation is either equivalent or it is not.

Table 4: Equivalent Transformation Attempts for Both Classes

\begin{tabular}{lllll}
\hline Data Set & Successful & Unsuccessful & Total & Rate \\
\hline All Classes & 1394 & 401 & 1795 & .778 \\
Period 1 & 732 & 241 & 973 & .752 \\
Period 3 & 662 & 160 & 822 & .805 \\
\hline
\end{tabular}

Interval or continuous measurements can be taken against the constraints by establishing the appropriate scale. The complexity of the transformation constitutes an interval scale in the sense that each kind of element represents 1 point on the scale. The constraints in the model for algebra referenced by the parser define the meaning of each element.

The binary nature of the dependent variable (equivalency of the transformation) indicates the use of logistic regression for statistical analysis. The logistic regression model characterizes the overall relationship between the independent and dependent variables. To account for repeated measures taken for each student and the potential influence of the differences between the two classes, student and class period were added as covariates. A plot of mean success rates (Figure 4a) has been added to show the influence of each level of complexity. The number of attempts students made at each level influences the interpretability of the mean as an indicator of the success at a particular level.

For example, in the original expression complexity chart below, only one attempt was made at level 6. The level 6 attempt was successful. The 100\% success rate at level 6 does not indicate that these students, or any other students in the class, will be equally successful given more attempts. As the 
(2016). Constraint-referenced analytics of algebra learning. Journal of Learning Analytics, 3(3), 143-169.

http://dx.doi.org/10.18608/jla.2016.33.8

number of attempts increases, a truer picture of success rate comes into focus. We have included the histogram (Figure $5 b$ ) showing the number of attempts at each level to clarify the meaning of the plots.

The cognitive complexity of the original expression had a moderate effect (eb=.603) but significant relationship to the success rate $(x 2=49.333, \mathrm{p}<.001, \mathrm{df}=1)$. The complexity of the transformation influenced the success rate $(\chi 2=165.990, p<.001, d f=1)$ to a much greater degree $(e b=.332)$.
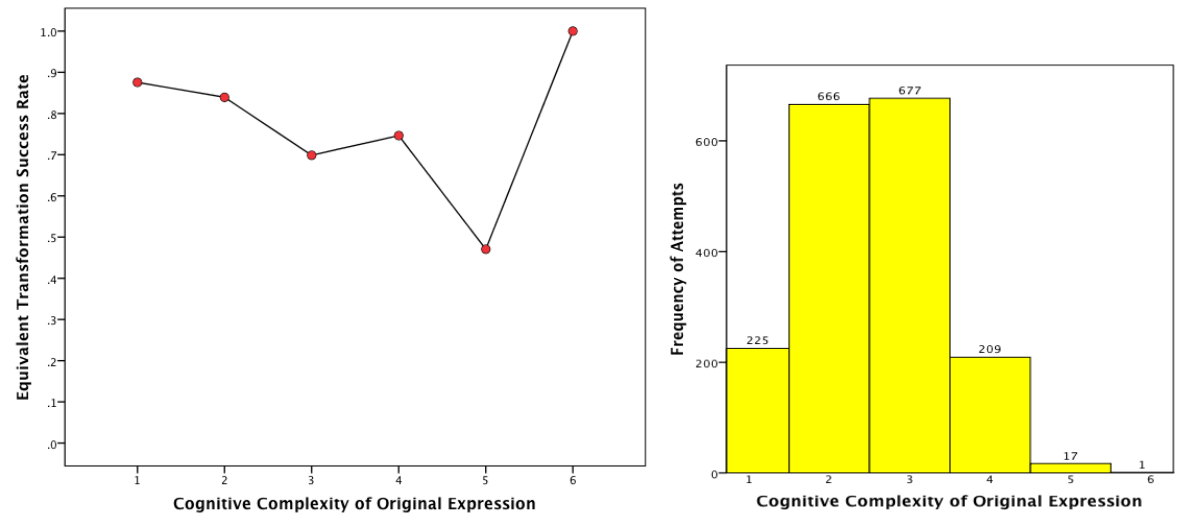

Figure 4: Cognitive Complexity of the Original Expression: a) Equivalent Transformation Success Rate; b) Frequency of Attempts
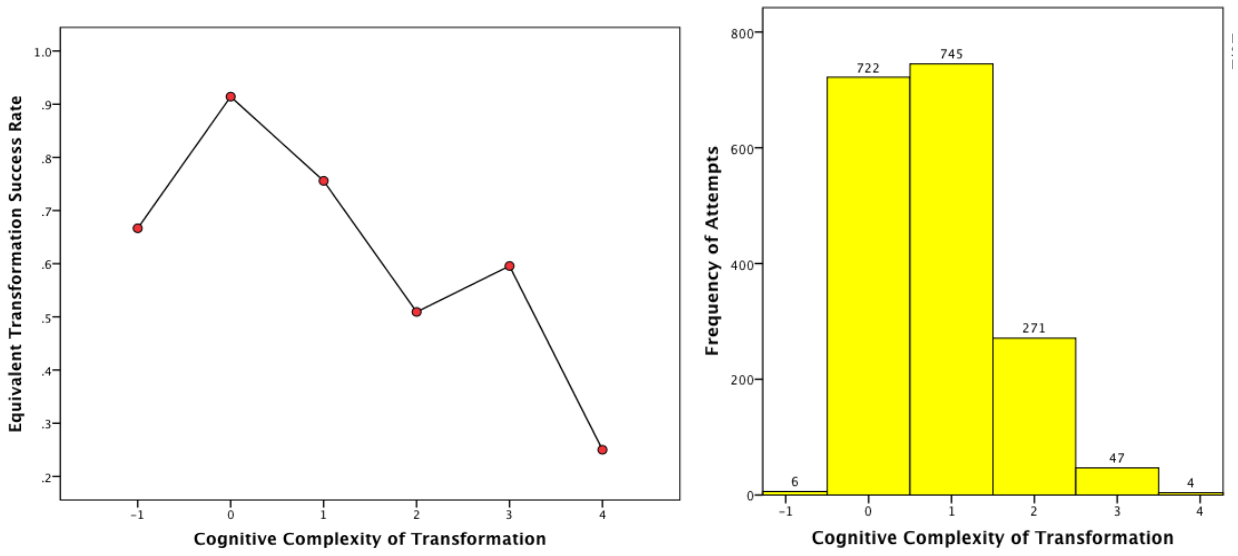

Figure 5: Complexity of the Transformation: a) Equivalent Transformation Success Rate; b) Frequency of Attempts

Table 5 summarizes the results of logistic regression analysis. Transformations became increasingly more difficult as students attempted to make larger changes in expression complexity. The complexity of the transformation was associated with a much greater decline in success rate than the complexity of the original expression. 
(2016). Constraint-referenced analytics of algebra learning. Journal of Learning Analytics, 3(3), 143-169.

http://dx.doi.org/10.18608/jla.2016.33.8

Table 5: Summary of Complexity Analysis for Both Classes.

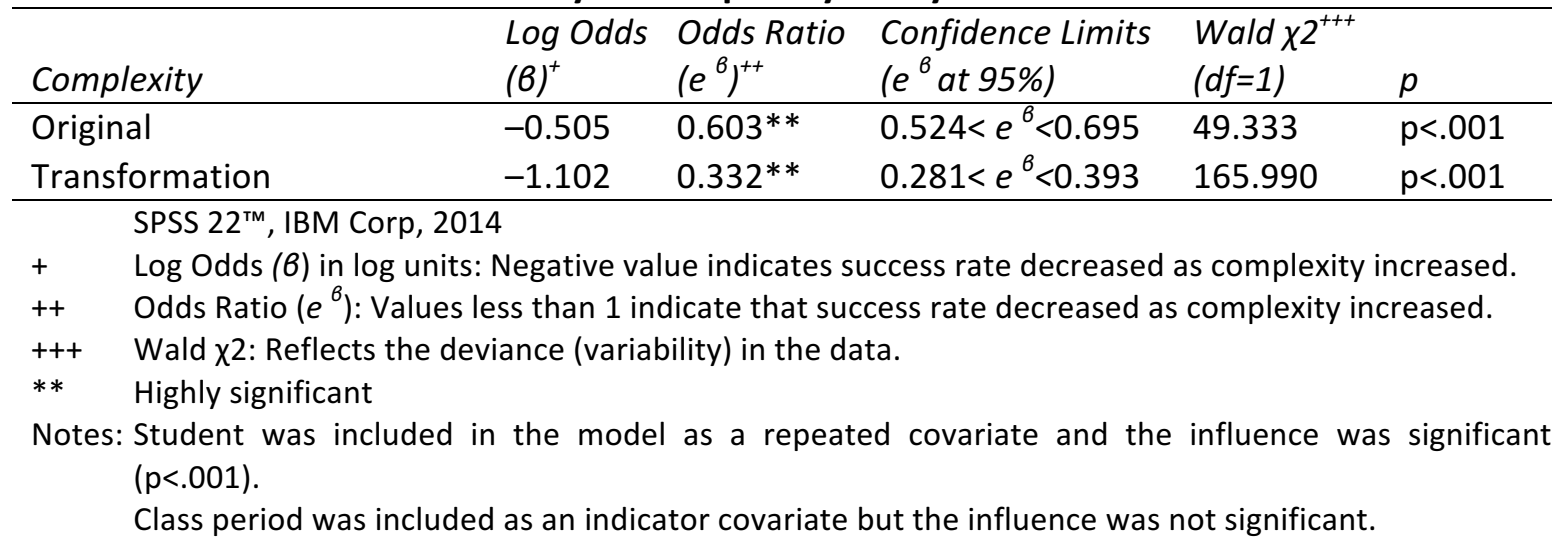

The Chi-squared statistic for transformations exceeded 150. This indicates that there was extensive deviance (variability) in the data and that the measurement instrument is sensitive to these differences. The high degree of significance indicates that the variability was highly systematic, even with students included as a repeated-measures covariate in the model. Taken together, these two statistics indicate that the cognitive analytics instrument measures the underlying construct and is highly discriminant, able to detect individual differences and individual trends over time.

\subsection{Reliability Across Classes}

Constraint-referenced analytics detect the influence on the success rate of the cognitive complexity of the transformation attempts as we have defined them here. It also takes into account the complexities of the original expression. Students recorded very few $(K=7$, less than $1 \%)$ attempts to increase the complexity of the expression. By definition, the complexity of the original expression limits the potential complexity of simplification, because the amount of decrease cannot exceed the complexity of the original expression, and even in simplest terms, an expression has a complexity value greater than zero. Furthermore, while the influence of the complexity of the original expression on the success rate is significant, it does not account for much of the variability in the data. For these reasons, the class level analyses have been restricted to the complexity of the transformation attempts themselves, since they always imply a certain minimum level of complexity in the original expression.

\subsubsection{Class Comparisons}

The influence of complexity on success rate for each class followed a strikingly similar pattern to the overall results. Table 6 shows the means, magnitude, significance, and frequency for the influence of complexity on success rate at each level by class. The low frequencies highlighted in gray indicate that the results may be a poor indicator of the true mean at that level of complexity. The negative Beta values indicate that success rate decreased as the level of complexity in the transformation increased. The size of the exponentiated Beta $\left(\mathrm{e}^{\boldsymbol{b}}\right)$ indicates the slope of the decrease - how much the success rate 
(2016). Constraint-referenced analytics of algebra learning. Journal of Learning Analytics, 3(3), 143-169. http://dx.doi.org/10.18608/jla.2016.33.8

decreased as the complexity increased. These results were highly significant and exerted a strong influence on the success rate for both the classes.

Table 6: Class Means and Statistics for Cognitive Complexity

\begin{tabular}{llllllllllll}
\hline Class & & $\mathbf{- 1}$ & $\mathbf{0}$ & $\mathbf{1}$ & $\mathbf{2}$ & $\mathbf{3}$ & $\mathbf{4}$ & $\boldsymbol{\beta}$ & $\mathbf{e}^{\boldsymbol{\beta}}$ & $\mathbf{p}<$ \\
\hline \multirow{2}{*}{ Class A } & Means & 0.00 & 0.91 & 0.72 & 0.53 & 0.56 & 0.25 & \multirow{2}{*}{-1.07} & $0.34^{*}$ & .001 \\
& Attempts & 1 & 348 & 392 & 174 & 36 & 4 & & & \\
& Means & 0.67 & 0.91 & 0.80 & 0.52 & 0.69 & 0.33 & & & \\
\multirow{2}{*}{ Class B } & Attempts & 3 & 370 & 312 & 125 & 16 & 3 & -1.14 & $0.32^{*}$ & .001 \\
& & & & & & & & & & \\
\hline
\end{tabular}

*Significant at $p<.001$

Figure 6 shows a chart of the mean success rates for both classes. The slightly higher success rate at complexity level 3 for Class $B$ is most likely influenced by the difference in number of attempts for Class $B(K=16)$ compared to Class $A(K=36)$. The mean success rate reflects a truer picture as the number of data points increases.

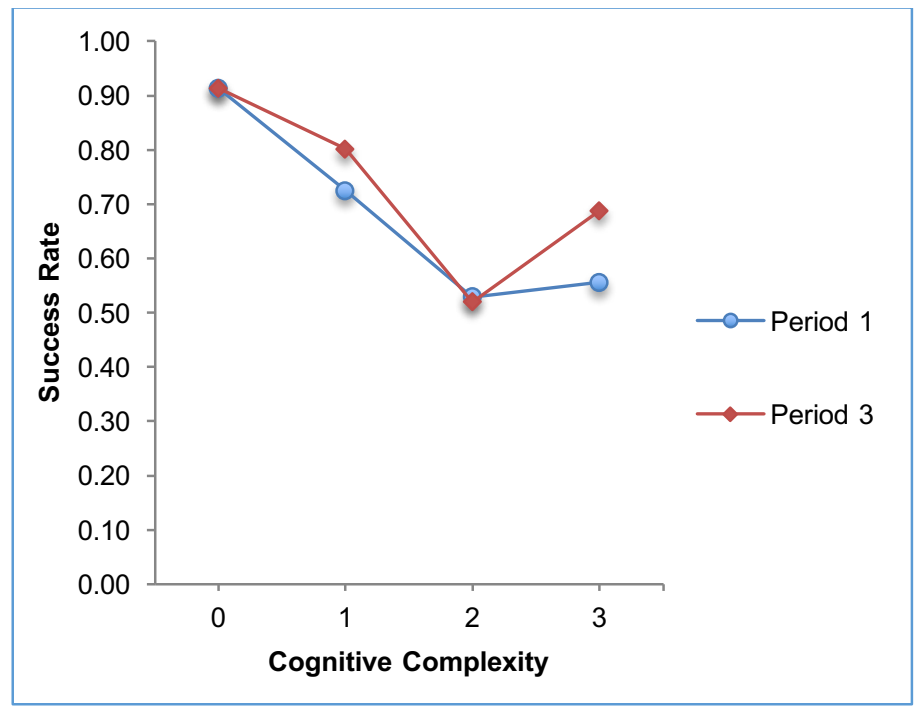

Figure 6: Class Success Rates by Complexity

\subsubsection{Tracking Individual Performance}

The results produced by the analytics engine can be used to trace the cognitive difficulty of sequences of transformation attempts - an automated form of repeated measures. By calculating a moving average of these repeated measures, a chart of performance over time can be produced. Table 7a shows success for each attempt and the complexity of each original expression and transformation. Table $7 \mathrm{~b}$ illustrates how performance was computed as a moving average of success rate over five attempts for the first ten attempts made by Bryon. Moving averages for success rate, cognitive complexity of the original expression and the cognitive complexity of the transformation are found in Table 7c. Calculations for ten attempts produce six averages. Each successive range is moved one attempt to the right across the data set. The resulting values show how success rate changes over time (Figure 7a). 
(2016). Constraint-referenced analytics of algebra learning. Journal of Learning Analytics, 3(3), 143-169.

Table 7a: Complexity and Success for Individual Equivalent Transformation Attempts

\begin{tabular}{lllllllllll}
\hline BRYON & ATT1 & ATT2 & ATT3 & ATT4 & ATT5 & ATT6 & ATT7 & ATT8 & ATT9 & ATT10 \\
\hline Success & 0 & 1 & 1 & 1 & 0 & 1 & 1 & 0 & 0 & 0 \\
Original & 2 & 2 & 2 & 2 & 3 & 3 & 4 & 3 & 3 & 3 \\
Transformation & 1 & 1 & 1 & 1 & 2 & 2 & 3 & 2 & 2 & 1
\end{tabular}

Table 7b: Moving Average as Success Rate Over a Range of 5 Attempts

\begin{tabular}{lllllllllll}
\hline Success & 0 & 1 & 1 & 1 & 0 & 1 & 1 & 0 & 0 & 0 \\
Success & 0 & 1 & 1 & 1 & 0 & 1 & 1 & 0 & 0 & 0 \\
Success & 0 & 1 & 1 & 1 & 0 & 1 & 1 & 0 & 0 & 0 \\
Success & 0 & 1 & 1 & 1 & 0 & 1 & 1 & 0 & 0 & 0 \\
Success & 0 & 1 & 1 & 1 & 0 & 1 & 1 & 0 & 0 & 0 \\
Success & 0 & 1 & 1 & 1 & 0 & 1 & 1 & 0 & 0 & 0 \\
Moving Average & 0.6 & 0.8 & 0.8 & 0.6 & 0.4 & 0.4 & & & & \\
\hline
\end{tabular}

Table 7c: Moving Averages for Success, Original Expression, and Transformation Complexity

\begin{tabular}{lllllll}
\hline BRYON & Range 1 & Range 2 & Range 3 & Range 4 & Range 5 & Range 6 \\
\hline Success & 0.6 & 0.8 & 0.8 & 0.6 & 0.4 & 0.4 \\
Original & 2.2 & 2.4 & 2.8 & 3 & 3.2 & 3.2 \\
Transformation & 1.2 & 1.4 & 1.8 & 2 & 2.2 & 2 \\
\hline
\end{tabular}

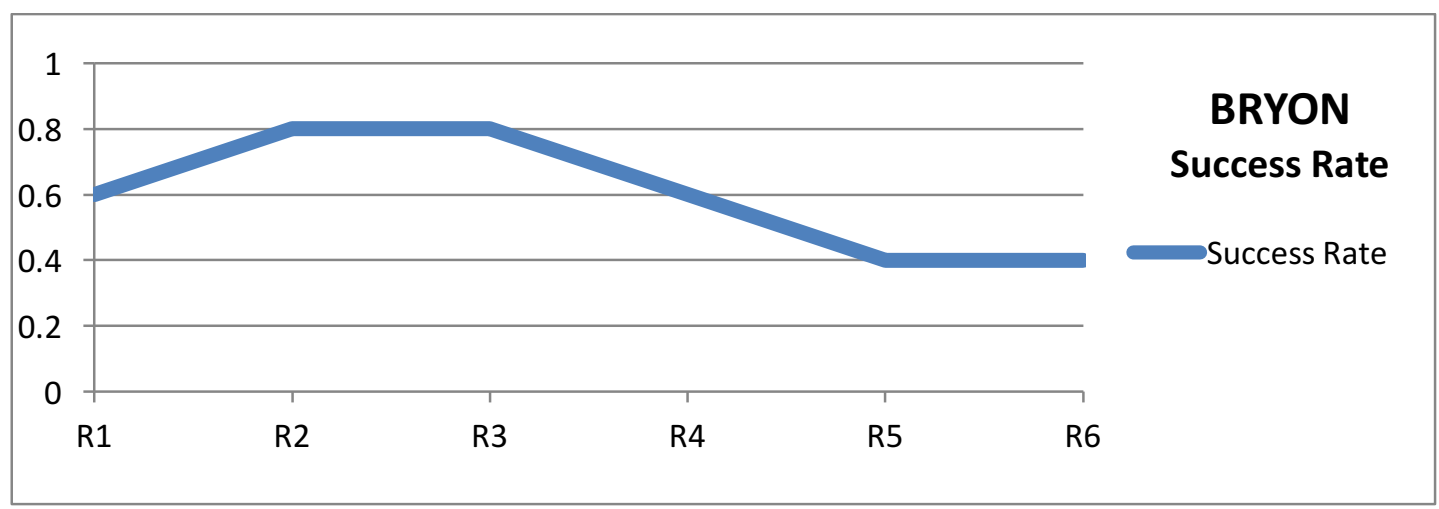

Figure 7a: Success Rate Over 10 Attempts Using a Moving Average for Every 5 Attempts

The moving averages for the cognitive complexity show how the original expression provided a context in which the transformation took place. The potential complexity of any attempt to simplify the original expression is limited by the complexity of the original expression. Bryon attempted to reduce the original expression to its simplest form in each case. The chart reveals that as the complexity of the 
(2016). Constraint-referenced analytics of algebra learning. Journal of Learning Analytics, 3(3), 143-169.

http://dx.doi.org/10.18608/jla.2016.33.8

original expression increased, so did the amount of change Bryon attempted to make during the transformation. This upward trend in complexity was accompanied by a downward trend in success rate.

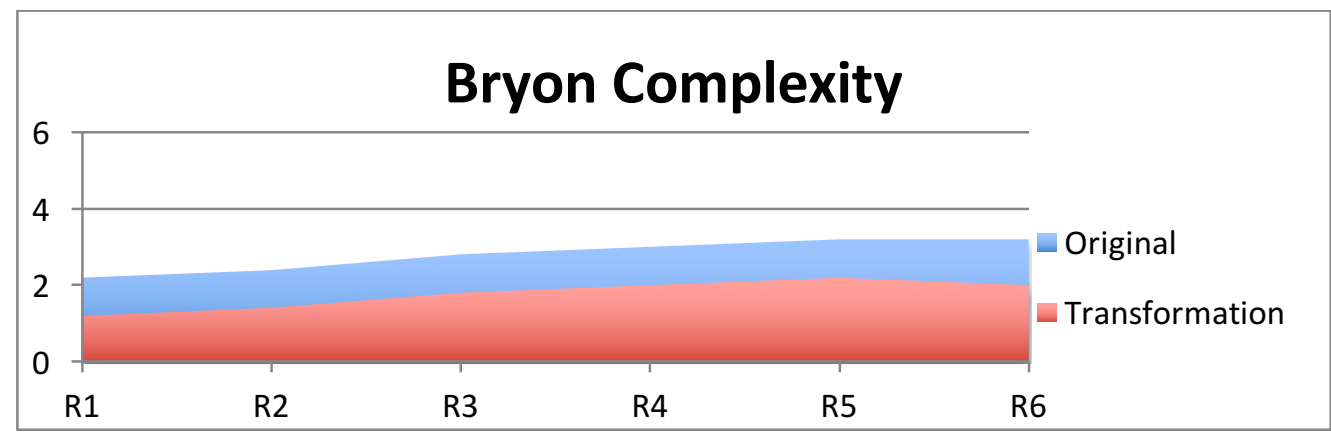

Figure 7b: Moving Average of Cognitive Complexity of Original Expression and Transformation

\subsubsection{Calculating Performance as the Product of Complexity and Success Rate}

Calculating performance as the product of transformation complexity and success rate reveals a clearer picture of Bryon's performance. The chart in Figure 8 represents the values found in Table 8 . The green area of Figure 8 represents cognitive performance, the proportion of transformation complexity for which Bryon made successful transformations. The exposed red portion shows the performance difference between expected performance and actual performance. A wide red area indicates a period of struggle when the student experienced a low success rate at a certain level of complexity. In this case, as the complexity level increased, performance decreased and the difference between actual and expected performance (the exposed red area) widened. Calculating success rate as a proportion of transformation complexity made it possible to chart performance over time.

Table 8: Performance Calculated by Success Rate as a Proportion of Transformation Complexity

\begin{tabular}{lllllll}
\hline BRYON & Range 1 & Range 2 & Range 3 & Range 4 & Range 5 & Range 6 \\
\hline Success & 0.6 & 0.8 & 0.8 & 0.6 & 0.4 & 0.4 \\
Transformation & 1.2 & 1.4 & 1.8 & 2 & 2.2 & 2 \\
Cognitive Performance & 0.7 & 1.1 & 1.4 & 1.2 & 0.9 & 0.8 \\
\hline
\end{tabular}

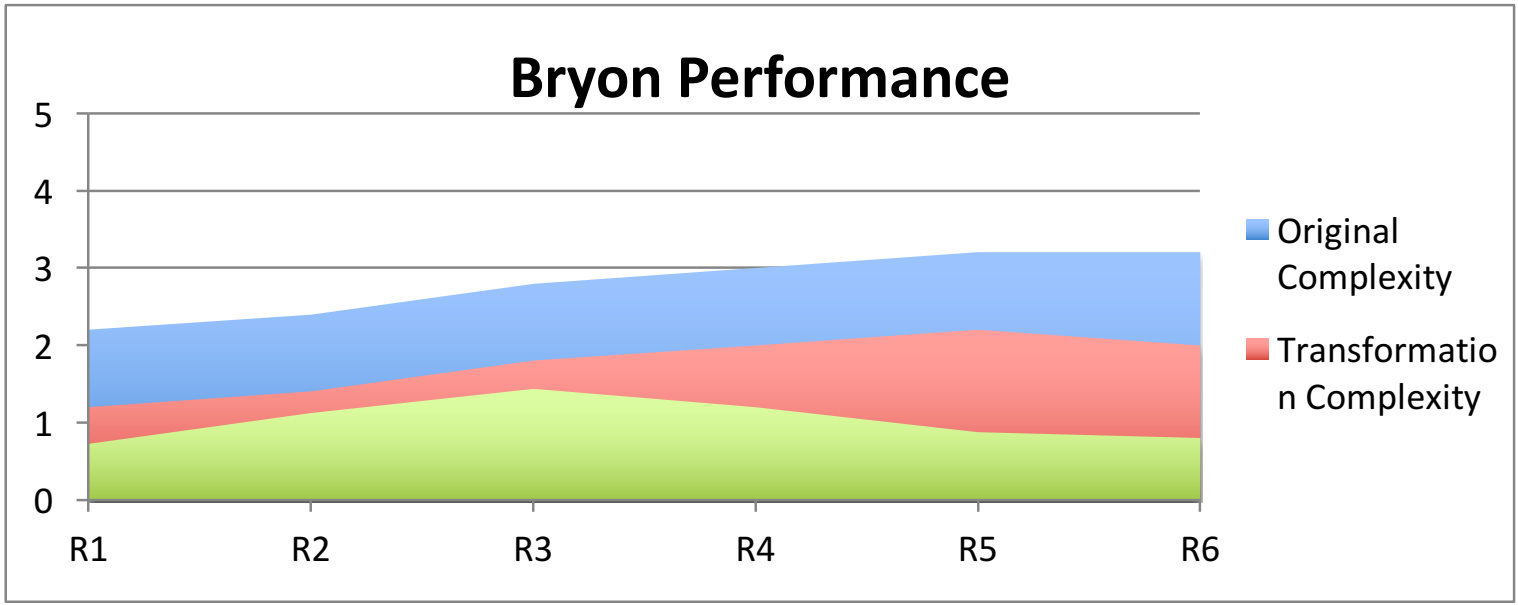


(2016). Constraint-referenced analytics of algebra learning. Journal of Learning Analytics, 3(3), 143-169.

\section{Figure 8: Performance Over Time}

\subsubsection{Analysis of Performance Charts}

Examination of performance charts for 49 students in Class A and Class B revealed that students experienced 92 periods of struggle and responded in three distinct ways: 1) they persisted in attempting similar transformations until they experienced a moment of insight that led to subsequent success; 2 ) they abandoned the struggle and switched to familiar transformations; or 3) they stopped participating either by entering no more inputs though they attended class, or depended entirely upon the partner to dictate inputs.

\subsubsection{Persistence That Led to a Conceptual Shift}

Michiko (Figure 9) experienced a period of struggle and was able to improve cognitive performance and gradually eliminate the performance difference by improving her success rate. She attempted 13 consecutive transformations with an average cognitive complexity of approximately 1 . She struggled initially as indicated by the wide performance difference from range R27 through R30 (eight attempts). She narrowed the performance difference by becoming more successful while maintaining a consistent level of cognitive complexity. The result was an increase in cognitive performance of nearly 1 complexity unit, eliminating the difference between expected performance (Transformation Complexity) and actual performance.

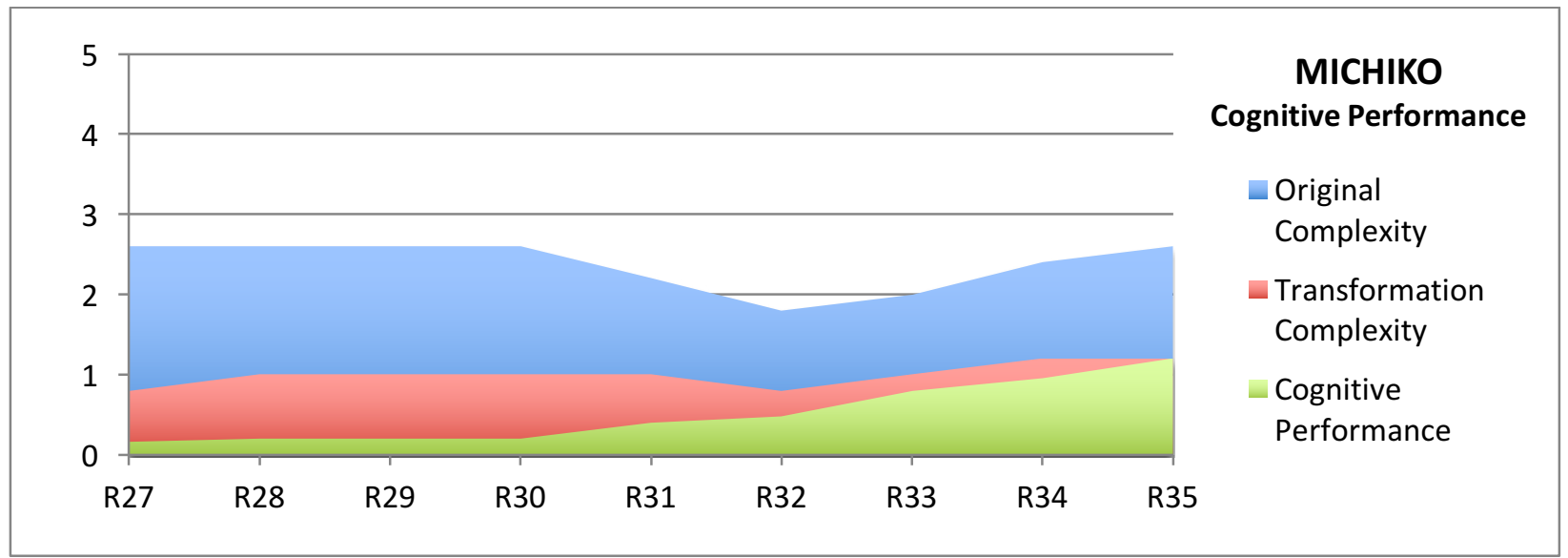

Figure 9: Improved Performance at Constant Level of Complexity

A look at the detailed record of attempts during that sequence reveals that Michiko gained understanding of the underlying principle that linear terms and constant terms must remain separate when combining like terms. 
(2016). Constraint-referenced analytics of algebra learning. Journal of Learning Analytics, 3(3), 143-169.

http://dx.doi.org/10.18608/jla.2016.33.8

Table 9: Sequence of Transformations Associated with Learning for Michiko

\begin{tabular}{|c|c|c|c|c|}
\hline Attempt & Partner & Original & Replacement & Success? \\
\hline 27 & Erik & $-2 X+1$ & $-1 X$ & No \\
\hline 28 & Erik & $-2 X+4 X$ & $2 X$ & Yes \\
\hline 29 & Erik & $2 X+1$ & $3 x$ & No \\
\hline 30 & Erik & $3 x-1-7 x$ & $10 x-1$ & No \\
\hline 31 & Erik & $3 x-1+-5$ & $3 x+6$ & No \\
\hline 32 & Tabatha & $4 X-1$ & $3 x$ & No \\
\hline 33 & Tabatha & $0+7 x$ & $7 X$ & Yes \\
\hline 34 & Tabatha & $7 X+2$ & $9 x$ & No \\
\hline 35 & Tabatha & $7 X+2 X$ & $9 x$ & Yes \\
\hline 36 & Tabatha & $9 X+X$ & $10 X$ & Yes \\
\hline 37 & Tabatha & $(10 x+-7)-(-7)$ & $10 x$ & Yes \\
\hline 38 & Tabatha & $10 x-(-6)$ & $10 X+6$ & Yes \\
\hline 39 & Tabatha & $10 X+6+-6$ & $10 X+0$ & Yes \\
\hline 40 & Tabatha & $10 x+0+-7$ & $10 X+7$ & No \\
\hline 41 & Tabatha & $10 x+0+-5$ & $10 x+5$ & No \\
\hline 42 & Tabatha & $10 x+0+-5$ & $10 x-5$ & Yes \\
\hline 43 & Tabatha & $10 x-5+-5$ & $10 X+0$ & No \\
\hline
\end{tabular}

All the transformations attempted by Michiko during this sequence involved combining like terms in linear expressions. Michiko mistakenly combined linear and constant terms (27-37), successfully making transformations only when the terms in the original expression were already alike $(28,35$, and 36$)$ or the constant term was a zero (33). A shift in understanding occurred beginning with attempt 37 . Michiko replaced $(10 x+-7)-(-7)$ with 10x, recognizing the underlying principle that the linear term $10 x$ and the constant terms -7 and -7 must be kept separate. Attempts 38 and 39 confirm that Michiko recognized unlike terms and combined them appropriately. Attempts 40 through 43 contain mistakes related to negative values, but linear and constant terms are not confused again in this sequence.

Michiko worked with two different partners. She made only one successful attempt when partnered with Erik (28), combining terms that were already alike in the original expression. She experienced success for the same reason when paired with Tabatha (35 and 36). The insight that led to the ability to differentiate linear and constant terms occurred when Michiko was paired with Tabatha. To what degree this shift in partnership led to new understanding is not clear from this record, since the same mistakes took place with both partners.

Only ten periods of struggle that led to better understanding of a principle underlying a procedure were found in this study. All periods of struggle that led to learning could be uniquely identified by the same five conditions. 
(2016). Constraint-referenced analytics of algebra learning. Journal of Learning Analytics, 3(3), 143-169.

http://dx.doi.org/10.18608/jla.2016.33.8

\section{Table 10: Conditions for Learning}

\begin{tabular}{ll}
\hline Span & Period of struggle spanned at least 7 attempts. \\
Complexity & The transformation complexity remained relatively constant. \\
Similarity & The student attempted similar transformations and made similar mistakes. \\
$\begin{array}{l}\text { Performance } \\
\text { Difference }\end{array}$ & A performance difference of at least $60 \%$ was eliminated during the sequence. \\
Conceptual Shift & The student experienced a conceptual shift and was subsequently successful. \\
\hline
\end{tabular}

\subsubsection{Abandoning the Struggle}

Marcel experienced a mild period of struggle prior to the extended period of success. The level of complexity decreased until the performance difference disappeared (Figure 10). A review of the record reveals that Marcel struggled with combining quadratic and linear terms and quickly switched to more familiar transformations.

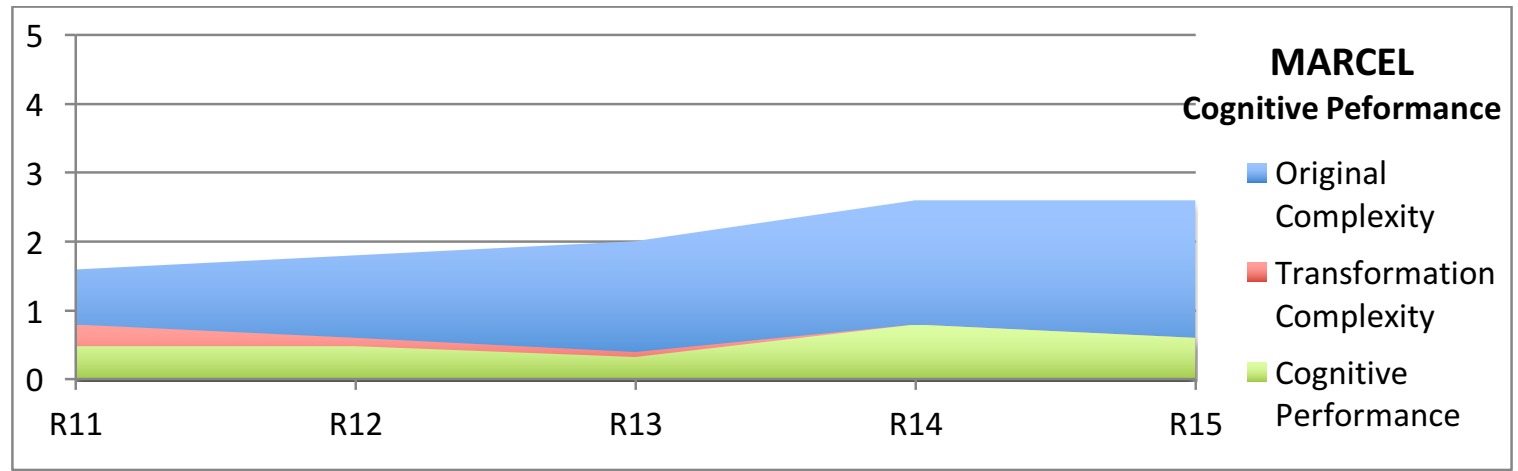

Figure 10: Period of Struggle Abandoned

Table 11: Marcel Avoided Quadratic Expressions

\begin{tabular}{ccccc}
\hline Attempt & Partner & Original & Replacement & Success? \\
\hline 11 & Darryl & $0+2 X^{2}$ & $2 X^{2}$ & Yes \\
12 & Darryl & $2 X^{2}+1$ & $3 X^{2}$ & No \\
13 & Darryl & $0+2 X^{2}$ & $2 X^{2}$ & Yes \\
14 & Darryl & $2 X^{2}+4 X^{2}$ & $6 X^{3}$ & No \\
15 & Darryl & $0+2 X$ & $2 X$ & Yes \\
16 & Darryl & $2 X+7 X$ & $9 X$ & Yes \\
17 & Darryl & $10 X-10+-3$ & $10 X-13$ & Yes \\
18 & Darryl & $10 X-20+-5$ & $10 X-25$ & Yes \\
19 & Darryl & $(-3 X)^{*}(-1)$ & $3 X$ & Yes \\
\hline
\end{tabular}

Marcel made four consecutive attempts to transform an expression with a quadratic binomial expression, experiencing success only when the constant term was zero (Attempts 11 and 13). To resolve the struggle, he returned to familiar linear expressions. He mistakenly replaced $2 x^{2}+1$ with $3 x^{2}$ (Attempt 12) and inappropriately incremented the exponent when he replaced $2 x^{2}+4 x^{2}$ with $6 x^{3}$ (Attempt 14). The struggle ended when he switched to linear expressions with consistent success. Marcel went on to make 15 consecutive successful transformations with linear expressions. Only two 
(2016). Constraint-referenced analytics of algebra learning. Journal of Learning Analytics, 3(3), 143-169.

http://dx.doi.org/10.18608/jla.2016.33.8

additional attempts to transform quadratic expressions were found in the record after this sequence one was successful and the other unsuccessful. Resolving the struggle meant avoiding the quadratic transformations that Marcel found difficult. Most periods of struggle followed the same pattern as Marcel (K=76).

\subsubsection{Non-Participation}

A few students chose non-participation in response to periods of struggle $(K=6)$. Four students attempted equivalent transformations during one or two sessions and subsequently ceased to participate at all though records indicate they attended class on the days the sessions were conducted.

Two students continued to input expressions into the calculators over several sessions. However, records show that increases and decreases in performance, as well as the kinds of transformations that could be successfully completed aligned with different partnerships. The case of Jessie illustrates this kind of non-participation by partner proxy.

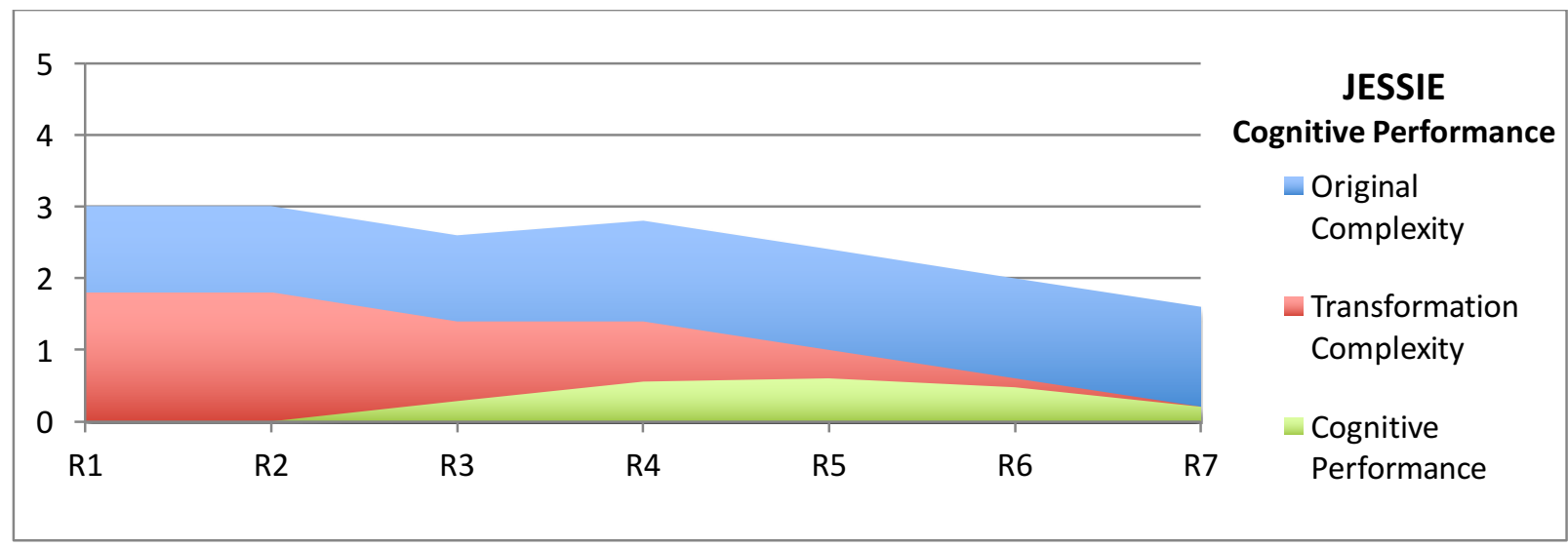

Figure 11: Non-participation by Partner Proxy

Jessie appears to narrow the performance difference by reducing the complexity of the transformations he attempted. The record shows that his apparent success can be explained by changes in partnership.

Table 12: Changes in Partnership Account for Success Rate

\begin{tabular}{ccccc}
\hline Attempt & Partner & Original & Replacement & Success? \\
\hline 1 & Arlene & $0+-7 X$ & 0 & No \\
2 & Arlene & $0-X+-5 X$ & 0 & No \\
3 & Arlene & $0-X+-6 X+7 X$ & $-14 X$ & No \\
4 & Arlene & $0-(-4)$ & 0 & No \\
5 & Arlene & $0-(-4)+4$ & 4 & No \\
6 & Arlene & $0-(-4)+7$ & 45552 & No \\
7 & Bryon & $X^{\wedge} 2+X+3+2 X+5 X+-5 X$ & $X^{\wedge} 2+3 X+3$ & Yes \\
8 & Jeffry & $7+7$ & 14 & Yes \\
9 & Jeffry & $14 * 2$ & 28 & Yes \\
10 & Jeffry & $4 * 7$ & 28 & Yes \\
\hline
\end{tabular}


(2016). Constraint-referenced analytics of algebra learning. Journal of Learning Analytics, 3(3), 143-169. http://dx.doi.org/10.18608/jla.2016.33.8

The chart for Jessie (Figure 11) reveals a modest increase in performance that might be associated with learning during an intense period of struggle. He was unable to complete any successful transformations in the first six attempts. When he switched partners and joined Bryon (Attempt 7), he was able to reduce a quadratic expression to simplest terms successfully. When he joined Jeffry, he was able to handle integer expressions (Attempts 8-10). Throughout the 12 sessions in which Jessie participated, success rate, complexity, and type of transformation were dependent upon the partnership. Jessie chose non-participation through partner proxy. This pattern was found for only one other participant.

Table 13: Summary of Performance Chart Analysis

\section{DISCUSSION}

\begin{tabular}{ll}
\hline Response & Count \\
\hline Learning & 10 \\
Challenge Reduction & 76 \\
Non-participation & 6 \\
\hline Total & 92 \\
\hline
\end{tabular}

Constraint-referenced analytics of algebra learning activities came from the two-fold desire to take a quantitative look at student responses in intentionally collaborative algebra activities, and to situate those activities in a more traditional introductory algebra classroom setting focusing on procedural understanding. Three constraint-based models were developed to measure the complexity of attempts to transform an algebraic expression by replacing it with an equivalent expression. The cognitive complexity model produced psychometrically verifiable results, showing decreased performance as complexity increased. The instrument proved to be highly discriminant, making an appropriate tool for measuring individual performance. The results were reliable across two classes of students with the same teacher. Monitoring student inputs over time revealed periods of struggle and three distinct patterns of student response to periods of struggle. Students who persisted by attempting similar transformations were eventually successful and were able to complete similar transformations afterwards. The majority of the students abandoned the transformations they found difficult and returned to more familiar algebraic forms. A few students chose to stop participating either by allowing their partner to guide their attempts or by ceasing to make any attempts at all. These patterns of response to struggle were consistent across two classes taught by the same teacher.

Students who persisted by repeatedly attempting similar transformations experienced an apparent conceptual shift in understanding. The case of Michiko illustrates this pattern of response as she attempted similar transformations until a moment of insight led to an apparent shift in understanding the underlying principle that linear and constant terms are different classes of mathematical objects and cannot be combined for a transformation to be equivalent. The other nine instances of learning were each accompanied by a similar apparent shift in understanding of a particular principle underlying the procedure being attempted. Whether these apparent conceptual shifts were associated with being taught and a matter of rote learning (Kapur, 2011), or whether they were discovered by the student was not observed. Additional independent evidence would be necessary to confirm the nature and depth of 
(2016). Constraint-referenced analytics of algebra learning. Journal of Learning Analytics, 3(3), 143-169. http://dx.doi.org/10.18608/jla.2016.33.8

a change in conceptual understanding. The difference between explicit and implicit conceptual knowledge is tightly tied to the task demands (Crooks \& Alibali, 2014). Students were not asked to explain their reasoning, so any suggestion of conceptual knowledge change can only be implicit in nature.

The students who participated in this study had been unsuccessful in a previous algebra class and were taking two periods of algebra simultaneously. It is not clear whether the heavy load of algebra classes contributed to the non-participation and challenge reduction rates reported here. It is possible that students enrolled in only one algebra class at a time would be more likely to persist during periods of struggle. The collaborative activity designs make it difficult for students to work alone. The study does not address the possibility that student willingness to persist was influenced by the partnership between students. It is also possible that student inputs were influenced by instruction from the teacher or by observation of other groups, making it prudent to take these results as a finding for the usefulness of the constraint-referenced analytics technique and a very preliminary description of the ways students respond to periods of struggle.

\section{CONCLUSION}

Despite significant limitations, the constraint-referencing engine designed for this study produced psychometrically verifiable results that made possible the tracking of student activity over time. Analysis did reveal periods of struggle and uniquely identified sequences in which a conceptual shift appeared to take place, consistent with a definition of conceptual understanding as knowledge of principles underlying procedures (Crooks \& Alibali, 2014). All cases of apparent learning featured a shift from struggle to success that may signal a conceptual shift. The analysis for this study took place post hoc. However, constraint-referenced analytics does not interrupt the learning process, making it possible to monitor algebraic transformation activities in real time. By making teachers aware when students are struggling, and by identifying patterns of response to the struggle, the system may become useful to support learning. The constraint-referenced analytics methods described here are in their earliest stages of development. The promising results presented here should be viewed as preliminary and exploratory.

Constraint-based models do define domains of knowledge based upon contextual patterns and are capable of capturing and encoding semantic meaning, but this study only makes use of this approach at the most fine-grained elemental level by encoding basic term types, negative symbols, and parentheses pairs. More full-featured grammars and pattern-matching technology can model complex and ill-defined domains of knowledge. Mathematical models can be developed to address multiple representations, operations, and patterns. Referencing constraints provides analytics developers a binary measure of success when actions fall inside or outside constraints. Models of difficulty can be developed based upon the number and kinds of constraints in play. Schemes for characterizing the relative influence of certain constraints over others promise to make models of complexity available for numerous domains of knowledge. 
(2016). Constraint-referenced analytics of algebra learning. Journal of Learning Analytics, 3(3), 143-169.

http://dx.doi.org/10.18608/jla.2016.33.8

\section{ACKNOWLEDGEMENTS}

This material is based upon work supported by the National Science Foundation under Grant No. DRL0747536, awarded to the second author.

\section{REFERENCES}

Ambrose, R., Baek, J., \& Carpenter, T. (2013). Children's invention of multidigit multiplication and division algorithms. In A. J. Baroody \& A. Dowker (Eds.), The development of arithmetic concepts and skills: Constructive adaptive expertise (p. 307). London: Routledge.

Baghaei, N., Mitrović, A., \& Irwin, W. (2007). Supporting collaborative learning and problem-solving in a constraint-based CSCL environment for UML class diagrams. International Journal of ComputerSupported Collaborative Learning, 2(2), 159-190. http://dx.doi.org/10.1007/s11412-007-9018-0

Baker, R. S., \& Inventado, P. S. (2014). Educational data mining and learning analytics. Learning Analytics (pp. 61-75). New York: Springer. http://dx.doi.org/10.1007/978-1-4614-3305-7_4

Ball, L., Pierce, R., \& Stacey, K. (2003). Recognising equivalent algebraic expressions: An important component of algebraic expectation for working with CAS. In N. A. Pateman, B. J. Dougherty, \& J. T. Zilliox (Eds.), Proceedings of the $27^{\text {th }}$ Conference of the International Group for the Psychology of Mathematics Education held jointly with the $25^{\text {th }}$ Conference of PME-NA (PME27/PME-NA 25), 13-18 July 2003, Honolulu, HI, USA. Retrieved from http://files.eric.ed.gov/fulltext/ED501048.pdf

Blikstein, P., Worsley, M., Piech, C., Sahami, M., Cooper, S., \& Koller, D. (2014). Programming pluralism: Using learning analytics to detect patterns in the learning of computer programming. Journal of the Learning Sciences, 23(4), 561-599. http://dx.doi.org/10.1080/10508406.2014.954750

Booth, L. R. (1988). Children's difficulties in beginning algebra. In A. F. Coxford \& A. P. Shulte (Eds.), The ideas of algebra, K-12. 1988 yearbook (pp. 299-306). Reston, VA: National Council of Teachers of Mathematics.

Chase, W. G., \& Simon, H. A. (1973). Perception in chess. Cognitive Psychology, 4(1), 55-81. http://dx.doi.org/10.1016/0010-0285(73)90004-2

Chi, M. T. H., Feltovich, P. J., \& Glaser, R. (1981). Categorization and representation of physics problems by experts and novices. Cognitive Science, 5(2), 121-152. http://dx.doi.org/10.1207/s15516709cog0502_2

Choppin, J. M., Clancy, C. B., \& Koch, S. J. (2012). Developing formal procedures through sense making. Mathematics Teaching in the Middle School, 17(9), 552-557. http://dx.doi.org/10.5951/mathteacmiddscho.17.9.0552

Crooks, N. M., \& Alibali, M. W. (2014). Defining and measuring conceptual knowledge in mathematics. Developmental Review, 34(4), 344-377. http://dx.doi.org/10.1016/j.dr.2014.10.001

Denmark, T., et al. (1976). Final report: A teaching experiment on equality. PMDC Technical Report No. 6, 158. Washington, DC: National Science Foundation. 
(2016). Constraint-referenced analytics of algebra learning. Journal of Learning Analytics, 3(3), 143-169.

http://dx.doi.org/10.18608/jla.2016.33.8

Filloy, E., \& Rojano, T. (1989). Solving equations: The transition from arithmetic to algebra. For the Learning of Mathematics, 9(2), 19-25.

Gattegno, C. (1974). The common sense of teaching mathematics. New York: Educational Solutions.

Henningsen, M., \& Stein, M. K. (1997). Mathematical tasks and student cognition: Classroom-based factors that support and inhibit high-level mathematical thinking and reasoning. Journal for Research in Mathematics Education, 28(5), 524-549.

Gobert, J. D., Sao Pedro, M., Raziuddin, J., \& Baker, R. S. (2013). From log files to assessment metrics: Measuring students' science inquiry skills using educational data mining. Journal of the Learning Sciences, 22(4), 521-563. http://dx.doi.org/10.1080/10508406.2013.837391

Halverson, R., \& Owen, V. E. (2014). Game-based assessment: An integrated model for capturing evidence of learning in play. International Journal of Learning Technology, 9(2), 111-138. http://dx.doi.org/10.1504/IJLT.2014.064489

Hiebert, J. (2013). Conceptual and procedural knowledge: The case of mathematics. London: Routledge.

Jones, I., Inglis, M., Gilmore, C., \& Dowens, M. (2012). Substitution and sameness: Two components of a relational conception of the equals sign. Journal of Experimental Child Psychology, 113(1), 166176. http://dx.doi.org/10.1016/j.jecp.2012.05.003

Jones, I., Inglis, M., Gilmore, C., \& Evans, R. (2013). Teaching the substitutive conception of the equals sign. Research in Mathematics Education, 15(1), 34-49. http://dx.doi.org/10.1080/14794802.2012.756635

Kapur, M. (2011). A further study of productive failure in mathematical problem solving: Unpacking the design components. Instructional Science, 39(4), 561-579. http://dx.doi.org/10.1007/s11251010-9144-3

Kapur, M. (2016). Examining productive failure, productive success, unproductive failure, and unproductive success in learning. Educational Psychologist, 51(2), 289-299. http://dx.doi.org/10.1080/00461520.2016.1155457

Kieran, C. (2004). The core of algebra: Reflections on its main activities. In K. Stacey, H. Chick, \& M. Kendal (Eds.), The future of the teaching and learning of algebra: The $12^{\text {th }}$ ICMI study (pp. 2133). New York: Springer. http://dx.doi.org/10.1007/1-4020-8131-6_2

Kieran, C. (1981). Concepts associated with the equality symbol. Educational Studies in Mathematics, 12(3), 317-326. http://dx.doi.org/10.1007/BF00311062

Kirshner, D. (199, April). The structural algebra option: A discussion paper. Paper Presented at the Annual Meeting of the American Educational Research Association (AERA), Atlanta, GA, USA. Retrieved from https://archive.org/stream/ERIC_ED364409/ERIC_ED364409_djvu.txt

Lai, K., \& White, T. (2012). Exploring quadrilaterals in a small group computing environment. Computers \& Education, 59(3), 963-973. http://dx.doi.org/10.1016/j.compedu.2012.04.006

Lai, K., \& White, T. (2014). How groups cooperate in a networked geometry learning environment. Instructional Science, 42(4), 615-637. http://dx.doi.org/10.1007/s11251-013-9303-4

Linchevski, L. (1995). Algebra with numbers and arithmetic with letters: A definition of pre-algebra. The Journal of Mathematical Behavior, 14(1), 113-120. http://dx.doi.org/10.1016/07323123(95)90026-8 
(2016). Constraint-referenced analytics of algebra learning. Journal of Learning Analytics, 3(3), 143-169.

http://dx.doi.org/10.18608/jla.2016.33.8

Linchevski, L., \& Herscovics, N. (1996). Crossing the cognitive gap between arithmetic and algebra: Operating on the unknown in the context of equations. Educational Studies in Mathematics, 30(1), 39-65. http://dx.doi.org/10.1007/BF00163752

Linchevski, L., \& Livneh, D. (1999). Structure sense: The relationship between algebraic and numerical contexts. Educational Studies in Mathematics, 40(2), 173-196. http://dx.doi.org/10.1023/A:1003606308064

McNeil, N. M., \& Alibali, M. W. (2005). Why won't you change your mind? Knowledge of operational patterns hinders learning and performance on equations. Child Development, 76(4), 883-899. http://dx.doi.org/10.2307/3696735

Mitrović, A. (2012). Fifteen years of constraint-based tutors: What we have achieved and where we are going. User Modeling and User-Adapted Interaction, 22(1), 39-72. http://dx.doi.org/10.1007/s11257-011-9105-9

Mitrović, A., Koedinger, K., \& Martin, B. (2003). A comparative analysis of cognitive tutoring and constraint-based modeling. User Modeling 2003, Lecture Notes in Computer Science, 2702, 313322. http://dx.doi.org/10.1007/3-540-44963-9_42

Mitrović, A., Mayo, M., Suraweera, P., \& Martin, B. (2001). Constraint-based tutors: A success story. Engineering of Intelligent Systems, Lecture Notes in Computer Science, 2070, 931-940. http://dx.doi.org/10.1007/3-540-45517-5_103

Mitrović, A., \& Weerasinghe, A. (2009). Revisiting ill-definedness and the consequences for ITSs. In V. Dimitrova, R. Mizoguchi, B. du Boulay, \& A. Graesser (Eds.), Artificial intelligence in education: Building learning systems that care: From knowledge representation to affective modelling (pp. 375-382). Amsterdam, Netherlands: IOS Press BV. http://dx.doi.org/10.3233/978-1-60750-0285-375

Muresan, S. (2013). Ontology-based semantic interpretation via grammar constraints. In new trends of research in ontologies and lexical resources (pp. 187-207). New York: Springer. http://dx.doi.org/10.1007/978-3-642-31782-8_10

Renninger, A., Hidi, S., \& Krapp, A. (Eds.) (2014). The role of interest in learning and development. New York: Psychology Press.

Rittle-Johnson, B., Siegler, R. S., \& Alibali, M. W. (2001). Developing conceptual understanding and procedural skill in mathematics: An iterative process. Journal of Educational Psychology, 93(2), 346. http://dx.doi.org/10.1037/0022-0663.93.2.346

Roll, I., Baker, R. S., Aleven, V., \& Koedinger, K. R. (2014). On the benefits of seeking (and avoiding) help in online problem-solving environments. Journal of the Learning Sciences, 23(4), 537-560. http://dx.doi.org/10.1080/10508406.2014.883977

Rossi, P. S. (2008). An uncommon approach to a common algebraic error. Primus, 18(6), 554-558. http://dx.doi.org/10.1080/10511970701678588

Saldanha, L., \& Kieran, C. (2005). A slippery slope between equivalence and equality: Exploring students' reasoning in the context of algebra instruction involving a computer algebra system. In G. M. Lloyd, M. Wilson, J. L. M. Wilkins, \& S. L. Behm (Eds.), Frameworks that Support Research and Learning: Proceedings of the $27^{\text {th }}$ Annual Meeting of the North American Chapter of the 
(2016). Constraint-referenced analytics of algebra learning. Journal of Learning Analytics, 3(3), 143-169.

http://dx.doi.org/10.18608/jla.2016.33.8
International Group for the Psychology of Mathematics Education (PME-NA 27), 20-23 October 2005,
Roanoke,
VA,
USA.
Retrieved
from

http://www.math.uqam.ca/ apte/Publications/Saldanha_Kieran_PMENA2005.pdf

Sfard, A. (1991). On the dual nature of mathematical conceptions: Reflections on processes and objects as different sides of the same coin. Educational Studies in Mathematics, 22(1), 1-36. http://dx.doi.org/10.1007/BF00302715

Sfard, A., \& Linchevski, L. (1994). The gains and the pitfalls of reification: The case of algebra. Educational Studies in Mathematics, 26(2-3), 191-228. http://dx.doi.org/10.1007/978-94-0172057-1_4

Sutherland, S. M., \& White, T. (2011). Differentiating algebraic equivalences in classroom networks. Proceedings of the $33^{\text {rd }}$ Annual Meeting of the North American Chapter of the International Group for the Psychology of Mathematics Education, Reno, NV, USA.

Wagner, S., \& Parker, S. (1993). Advancing algebra. In P S. Wilson (Ed.), Research ideas for the classroom: High school mathematics, 119-139. New York: Macmillan.

Warren, E. (2003). The role of arithmetic structure in the transition from arithmetic to algebra. Mathematics Education Research Journal, 15(2), 122-137. http://dx.doi.org/10.1007/BF03217374

White, T. (2006). Code talk: Student discourse and participation with networked handhelds. International Journal of Computer-Supported Collaborative Learning, 1(3), 359-382. http://dx.doi.org/10.1007/s11412-006-9658-5

White, T. (2009). Encrypted objects and decryption processes: Problem-solving with functions in a learning environment based on cryptography. Educational Studies in Mathematics, 72(1), 17-37. http://dx.doi.org/10.1007/s10649-008-9180-y

White, T. (2013). Networked technologies for fostering novel forms of student interaction in high school mathematics classrooms. In C. Mouza \& N. Lavigne (Eds.), Emerging technologies for the classroom (pp. 81-92). New York: Springer. http://dx.doi.org/10.1007/978-1-4614-4696-5_6

White, T., \& Lai, K. (2008). Collaborative problem solving with linked representational tools. http://citeseerx.ist.psu.edu/viewdoc/download?doi=10.1.1.372.9314\&rep=rep1\&type=pdf

White, T., \& Pea, R. (2011). Distributed by design: On the promises and pitfalls of collaborative learning with multiple representations. Journal of the Learning Sciences, 20(3), 489-547. http://dx.doi.org/10.1080/10508406.2010.542700

White, T., Sutherland, S. M., \& Lai, K. (2010). Constructing collective algebraic objects in a classroom network. In P. Brosnan, D. B. Erchick, \& L. Flevares (Eds.), Optimizing Student Understanding in Mathematics: Proceedings of the $32^{\text {nd }}$ Annual Meeting of the North American Chapter of the International Group for the Psychology of Mathematics Education (PME-NA 32), 28-31 October 2010, Columbus, OH, USA (pp. 1523-1530).

White, T., Wallace, M., \& Lai, K. (2012). Graphing in groups: Learning about lines in a collaborative classroom network environment. Mathematical Thinking and Learning, 14(2), 149-172. http://dx.doi.org/10.1080/10986065.2012.656363 
JOURNAL OF LEARNING ANALYTICS

(2016). Constraint-referenced analytics of algebra learning. Journal of Learning Analytics, 3(3), 143-169.

http://dx.doi.org/10.18608/jla.2016.33.8

Wilensky, U. (1999). NetLogo. [Computer Software]. Retrieved from http://ccl.northwestern.edu/netlogo/

Wilensky, U., \& Stroup, W. (1999). HubNet. Evanston, IL: Center for Connected Learning and ComputerBased Modeling, Northwestern University. http://ccl.northwestern.edu/ps 